\title{
Feasibility study of using fly ash brick made from reclaimed sand dust waste and quarry dust waste
}

\begin{abstract}
In India, Metal Casting Industry are one of the oldest and distributed sector. Most of this industry preferred sand casting molding system for casting of metal. A large quantity of sand waste is generated by reclamation process in cyclone separator and bag filter. This generated sand waste is disposed in landfill site and dumping site. Disposal of sand dust waste causes environmental pollution. Thus reclaimed sand dust waste has become an environmental menace. The paper here presents utilization of RSDW (Reclaimed sand dust Waste) in fly ash brick as a replacement material of fly ash. RSDW is replaced with fly ash in different proportions like $20 \%, 40 \%, 60 \%, 80 \%$, and $100 \%$. In this paper detail discussion of compressive test and result is represented.
\end{abstract}

Keywords: wind turbine blade waste, hazardous waste, environmental preservation, waste utilization, resource conservation, environmental pollution, hazardous waste recycle
Volume 3 Issue 3 - 2017

\author{
Ajay Andodariya,' Reshma L Patel, ${ }^{2}$ \\ Jayeshkumar Pitroda ${ }^{2}$ \\ 'Final year M. Tech. Student, Environmental Engineering, India \\ ${ }^{2}$ Associate Professor, Civil Engineering Department, India
}

\begin{abstract}
Correspondence: Ajay Andodariya, Final year M.Tech. Student, Environmental Engineering, B.V.M Engineering College,V.V Nagar, India, Email ajayandodariya03@gmail.com
\end{abstract}

Received: May 17, 2017 | Published:September 08, 2017

\section{Introduction}

Most of Metal Casting Industry preferred sand casting moulding system for casting of metal. Reclaimed sand dust waste is by product of making metal casting. Waste sand is major problem for Indian Small and medium scale metal casting industry. Metal casting process generate several kinds of waste, Reclaimed waste sand is the main waste. Since this industry make intensive use of sand as primary direct material, the regeneration of this sand can be considered as main factor in environmental performance to achieve sustainable development. In India small and medium scale metal casting industries are not aware of this fact. They are ignoring problems, since last decade. But now a day it is essential to focus on sand regeneration, recycling, re-use and disposal for sustainable development in metal casting industries. ${ }^{1}$ In recent years the metal casting industry has been showing an increased interest in reclamation of system sands. One problem that confronts every industry is that of processing an adequate supply of sand which has the properties to meet the many requirements imposed upon it in moulding and core making. The volume of sand waste generation presents a major handling problem in this industry. ${ }^{2}$ Environmentally, it is becoming more and more difficult to dispose of great quantities of material into the ground. Different agencies and Governments want to know what chemicals are in all refuse and what amount might leach out from the sand. This interest is not only in the public dumps but on the industry's own property. Also Reclaimed sand dust waste is particulate type matter so that's why it causes human health problem near to dumping site of waste.

Sand dust waste from metal casting industry becomes environmental issue, due to its haphazard disposal. Same time Popularity of using environmental friendly, low cost and lightweight construction materials increasing in construction industry. Because of this need to investigate how this can be achieved by benefiting the environment with maintain the material requirements according to standard. Using of industrial waste and agricultural activities waste as raw material for construction to be viable solution for economic design of building. It is also beneficial to environment for waste management and disposal of industrial hazardous waste If we recycle and reuse this industrial waste then we can easily reduce quantum of industrial waste and treat it better way for disposal. The brick industry is the most indicated technological activity sector to absorb solid waste due to the large quantity of raw material used by the sector as well as by the large volume of final products in construction (Figure 1). Brick is one of the most commonly used construction material. Nowadays Fly ash bricks are most useable bricks in sustainable construction. The main raw materials from which it is prepared; Fly ash and Lime affect both the quality and cost of construction. Fly ash constitutes over $70 \%$ the total volume of brick. The availability and proximity of fly ash to the construction site also affect the cost of construction. As rapid construction and development is going on use of fly ash has also rapidly increased. So that raw material cost for fly ash brick production is increasing due to lack of availability of fly ash. To address this situation attention has been shifted to low cost or waste material which can be used as building material. ${ }^{3,4}$ According to Ajay A et al. ${ }^{5}$ there is rapidly increase in generation of industrial solid waste and problems of waste disposal. Other sides recycle and reuse of this industrial waste in construction industry as raw material increasing. So that which different kind of industrial solid waste we can use in brick production is discussed in this paper. ${ }^{6,7}$
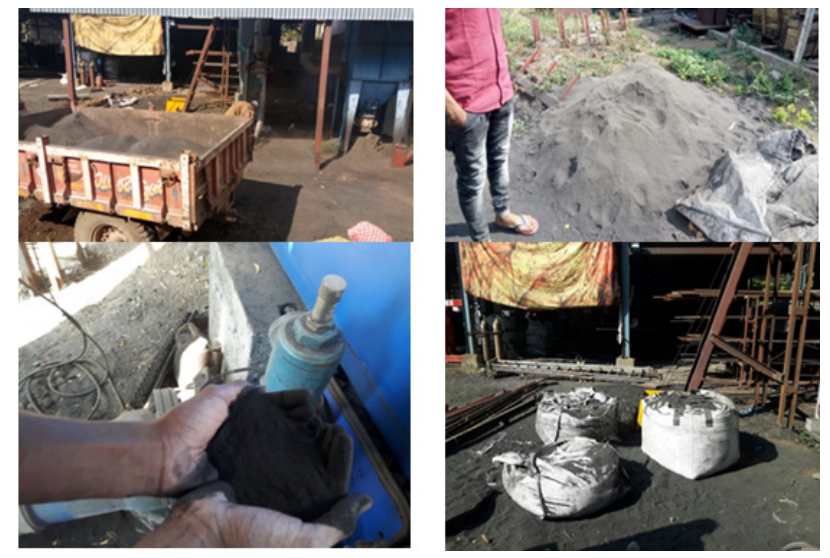

Figure I Reclaimed sand dustWaste (Source: Rhino Machines Pvt. Ltd., GIDC, V.U Nagar,Anand). 


\section{Experimental materials}

Fly ash bricks are lighter and stronger than clay bricks. Main ingredients include fly ash, water, quicklime or lime sludge.

Following are the experimental materials for the research experimental work:

\section{Fly ash}

Fly ash is used as a supplementary cementitious material (SCM) in the production of fly ash brick. A supplementary cementitious material, when used contributes to the properties of the hardened to brick through hydraulic or pozzolanic activity, or both. We use Class $\mathrm{F}$ for our reclaimed sand brick manufacturing research purpose. Chemical properties of fly ash using for research work is given in Table 1.

Table I Chemical Composition of Fly ash and RSD waste

\begin{tabular}{lll}
\hline $\begin{array}{l}\text { Chemical composition } \\
\text { (in percent by Mass) }\end{array}$ & Fly ash & $\begin{array}{l}\text { Reclaimed sand } \\
\text { dust waste }\end{array}$ \\
\hline Aluminium oxide $\left(\mathrm{Al}_{2} \mathrm{O}_{3}\right)$ & 4.38 & 16.64 \\
Silicon dioxide $\left(\mathrm{SiO}_{2}\right)$ & 57.69 & 38.7 \\
Magnesium oxide $(\mathrm{MgO})$ & 5.9 & 30.57 \\
sulphur trioxide $\left(\mathrm{SO}_{3}\right)$ & 0.25 & 2.67 \\
sodium oxide $\left(\mathrm{Na}_{2} \mathrm{O}\right)$ & 0.36 & 0.63 \\
\hline
\end{tabular}

\section{Reclaimed sand dust waste}

Waste material required for this project which is reclaimed sand dust waste is collected from Rhino Machines Pvt. Ltd., GIDC, Vitthal Udhyog Nagar, Anand. Waste is collected around $400 \mathrm{~kg}$ for this research work and transported to fly ash brick manufacturing industry. Chemical properties of reclaimed sand dust waste using for research work is given in Table 1 .

\section{Sludge lime}

The pozzolanic reactivity of fly ash is more in high calcium fly ash. The greater the pozzolanic activity leads to higher the strength of fly ash brick. Because of that sludge lime is used for our project work related to fly ash brick production.

\section{Quarry dust}

Quarry Dust or fine Sand use as binder material in fly ash brick production. Quarry dust is collected from the local distributers for the project work.

\section{Chemical composition of Fly ash and RSD waste}

The following table shows the chemical composition of fly ash and reclaimed sand dust waste which are using for this research work (Table 1).

\section{Brick mixes}

Fly ash Brick mixes with replacement of fly ash by reclaimed sand dust waste is done. As shown in Table 2 and same were used to prepare various batches of brick for replacement of fly ash by reclaimed sand dust waste. The brick mixes proportions are shown in Table 2. Reclaimed sand dust waste is than replaced with fly ash in different proportions. In this work we prepared eight batches of brick consisting standard fly ash brick (A), 20\% replacement of fly ash (B1), $40 \%$ replacement of fly ash, $60 \%$ replacement of fly ash with $15 \%$ inclusion of quarry dust and without replacement of fly ash (C1), $25 \%$ replacement of fly ash (C2), $50 \%$ replacement of fly ash (C3), $75 \%$ replacement of fly ash (C4) without inclusion of quarry dust.

Table 2 Replacement of Fly Ash by RSD Waste in Fly Ash Bricks

\begin{tabular}{lllll}
\hline Brick mixes & Fly ash $\mathbf{( K g )}$ & RSDW $\mathbf{( K g )}$ & Quarry dust $\mathbf{( K g )}$ & Sludge lime \\
\hline A (0\%) & 60 & 0 & 15 & 25 \\
BI (20\%) & 40 & 20 & 15 & 25 \\
B2 (40\%) & 20 & 40 & 15 & 25 \\
B3 (60\%) & 0 & 60 & 15 & 25 \\
CI (00\%) & 75 & 0 & 0 & 25 \\
C2 (25\%) & 50 & 25 & 0 & 25 \\
C3 (50\%) & 25 & 50 & 0 & 25 \\
C4 (75\%) & 0 & 75 & 0 & 25 \\
\hline
\end{tabular}

RSDW, Reclaimed Sand Dust Waste;

Where, $\mathrm{A}$ is conventional fly ash brick, $\mathrm{BI}$ to $\mathrm{B} 3$ and $\mathrm{Cl}$ to $\mathrm{C} 4$ are reclaimed sand dust brick in different proportion

\section{Experimental methodology}

Fly ash, lime, sand and gypsum are manually fed into a pan mixer where water is added in the required proportion for intimate mixing. The materials are mixed in pan mixture. The homogenised mortar taken out of roller mixer is put into the mould boxes. Depending on the type of machine, the product is compacted under vibration / hydraulic compression etc. The bricks are dried up under sun from 24 to 48 hours, depending whether lime route. The dried up bricks are stacked and subjected for water spray curing once or twice a day, for 7-21 days, depending on ambience. The bricks are tested for compressive strength test at 7 days, 14 days, 21 days respectively and after 21 days water absorption test also done. 


\section{Compressive Strength Test Results [IS 3495:I992 Part 1]}

Compressive strength tests were performed on compression testing machine using brick samples. Three samples per batch were tested with the average strength values reported in this paper. Remove unevenness observed in the bed faces to provide two smooth and parallel faces by grinding from the brick sample. The sample has been stored in water at room temperature for 24 hours. Then prepare cement mortar (1:1) and fill the frog. Store the sample prepared under damp jute bag for 3 days in clean water. Remove and wipe out a trace of moisture. Measure the area of two horizontal faces. Place the specimen with flat faces horizontal and mortar filled facing upwards between two plywood sheets and centre carefully between plates of testing machine. Load is applied axially at a uniform rate $14 \mathrm{~N} / \mathrm{mm}^{2}$ per minute till failure occurs and the maximum load at failure is noted (Figure 2) (Table 3).

Table 3 Comparative Experimental Results of Compressive Strength Test for Brick Mixes: Conventional Fly Ash Brick and Fly Ash Brick with Replacement of RSDW in Different Proportions

\begin{tabular}{llll}
\hline & \multicolumn{3}{c}{ Average compressive strength (N/mm } \\
\cline { 4 - 4 } Brick Mixes & $\mathbf{7}$ Days & 14 days & 21 days \\
\hline Fly Ash Brick & & & 12.87 \\
A (00\%) & 12.35 & 12.7 & \\
Fly Ash Bricks with RSD Waste and Quarry Dust & & & 21.82 \\
BI $(20 \%)$ & 11.32 & 13.14 & 18.38 \\
B2 $(40 \%)$ & 10.96 & 11.3 & 12.66 \\
B3 $(60 \%)$ & 6.24 & 6.8 &
\end{tabular}

Fly Ash Bricks with only RSD Waste

$\begin{array}{lccr}\text { CI }(00 \%) & 10.57 & 11.42 & 11.94 \\ \text { C2 }(25 \%) & 12.6 & 13.14 & 14.9 \\ \text { C3 }(50 \%) & 9.6 & 11.42 & 15.29 \\ \text { C4 }(75 \%) & 5.39 & 7.03 & 10.43\end{array}$

Fly Ash Brick

$\begin{array}{llll}\text { A }(00 \%) & 12.35 & 12.7 & 12.87\end{array}$

Fly Ash Bricks with RSD Waste and Quarry Dust

$\begin{array}{lccc}\text { BI }(20 \%) & 11.32 & 13.14 & 21.82 \\ \text { B2 }(40 \%) & 10.96 & 11.3 & 18.38 \\ \text { B3 }(60 \%) & 6.24 & 6.8 & 12.66\end{array}$

Fly Ash Bricks with only RSD waste

$\begin{array}{lccc}\text { CI }(00 \%) & 10.57 & 11.42 & 11.94 \\ \text { C2 }(25 \%) & 12.6 & 13.14 & 14.9 \\ \text { C3 }(50 \%) & 9.6 & 11.42 & 15.29 \\ \text { C4 }(75 \%) & 5.39 & 7.03 & 10.43\end{array}$



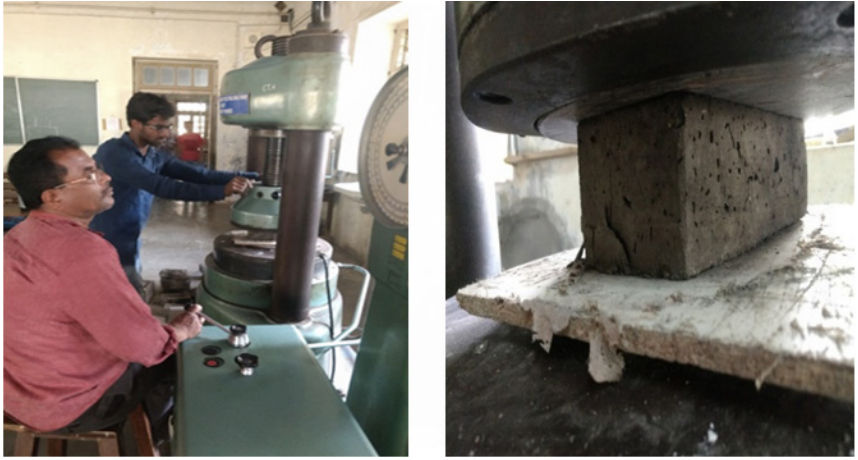

Figure 2 Setup of Compression compressive strength testing machine (At BVM Engineering college testing laboratory).

From above Figures 3, it can be said that compressive strength of brick mixes increased day by day. Also compressive strength at 21 days increases with replacement of RSD waste $20 \%$ than decreases for $40 \%$ and $60 \%$ but for $40 \%$ and $60 \%$ replacement of RSD waste gives comparable compressive strength compare to conventional fly ash brick. So optimum RSD waste replacement for maximum compressive strength was $20 \%$. For $20 \%$ B1 mix shows $58.98 \%$ increase in compressive strength to conventional A mix. At $20 \%$ replacement B1 mix shows $21.82 \mathrm{~N} / \mathrm{mm}^{2}$ maximum compressive strength after 21 days.

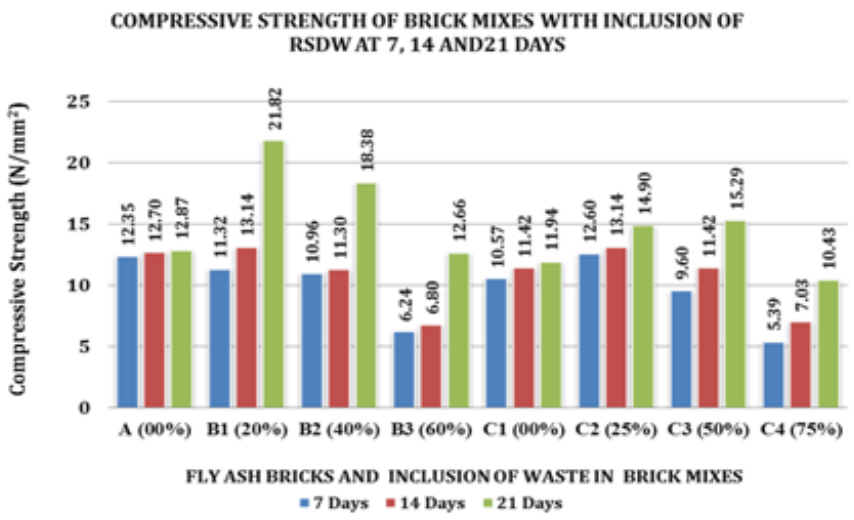

Figure 3 Compressive Strength of Brick Mixes: Conventional Fly Ash Brick and Fly Ash with Replacement of RSDW in Different Proportionate 7, 14, 28 Days.

\section{Water absorption (IS 3495: 1992 Part II) (24-hour immersion cold water test)}

Dry the specimen in a ventilated oven at a temperature of 105 to $115^{\circ} \mathrm{C}$ till it attains substantially constant mass. Cool the specimen to room temperature and obtain its weight (Dry Weight). Specimen warm to touch shall not be used for the purpose. Immerse completely dried specimen in clean water at a temperature of $27 \pm 2^{\circ} \mathrm{C}$ for 24 hours. Remove the specimen and wipe out any traces of water with a damp cloth and weigh the specimen. Complete the weighing 3 minutes after the specimen has been removed from water (wet weight). Water absorption, percent by mass, after 24 -hour immersion in cold water is given by formula (Table 4). From above Figure 4, it can be said that for brick mixes percentage water absorbed was increases with increase in replacement of RSD waste with fly ash but every mixes shows percentage water absorbed is acceptable in range. Optimum result for water absorption obtained in B1 batch in which $20 \%$ replacement of fly ash by RSD waste. Maximum result for water absorption obtained in $\mathrm{C} 4$ batch. Result for water absorption test shows that B2, B3, C2, $\mathrm{C} 3$ batches gave less results compare to conventional fly ash brick.

Table 4 Comparative Experimental Results of Water Absorption Test for Brick Mixes: Conventional Fly Ash Brick and Fly Ash Brick with Replacement of RSDW in Different Proportions

\begin{tabular}{ll}
\hline Brick mixes & Water absorption (\%) (By mass) \\
\hline A (00\%) & 10.1 \\
BI (20\%) & 8.1 \\
B2 (40\%) & 8.2 \\
B3 (60\%) & 9.5 \\
CI (00\%) & 10.6 \\
C2 (25\%) & 9.1 \\
C3 (50\%) & 8.5 \\
C4 (75\%) & 12.1
\end{tabular}

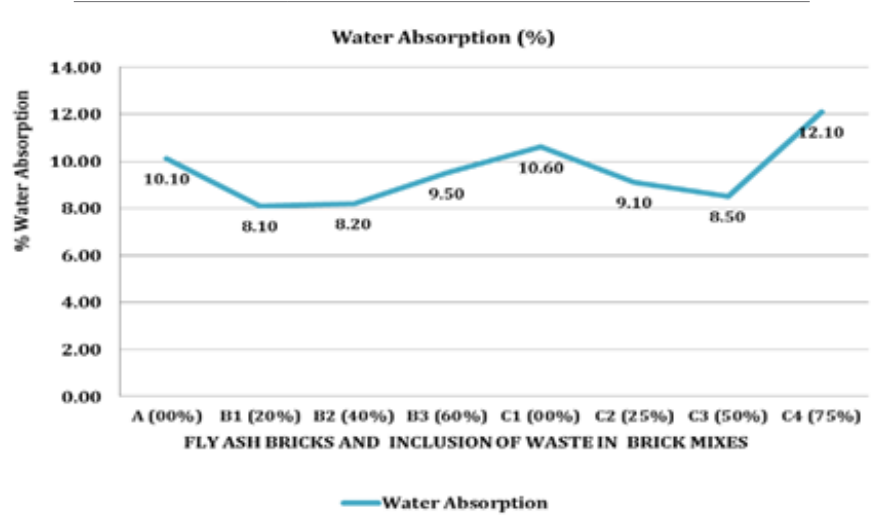

Figure 4 Water Absorption of Brick Mixes: Conventional Fly Ash Brick and Fly Ash with Replacement of RSDW in Different Proportion.

\section{Conclusion}

From the above experimental test, following conclusion is drawn:

1. Compressive strength of brick was increasing by replacement of RSDW in different proportion for fly ash as compared to conventional fly ash brick.

2. Results shows that optimum RSDW Replacement for highest compressive strength is $20 \%$, and it also indicate that compressive strength decreases with replacement of fly ash with RSDW and quarry dust waste.

3. Water absorption capacity increases with percentage replacement of RSDW increase respectively, but all bricks made with use of RSDW gives lower water absorption compare to convention brick.

4. B1 batch of brick made with $20 \%$ replacement shows $21.82 \mathrm{~N} /$ $\mathrm{mm}^{2}$ compressive strength which is $76.68 \%$ more than compare to compressive strength of conventional fly ash brick.

5. Also $\mathrm{B} 1$ batch of brick gives $8.10 \%$ water absorption by mass which is desirable compare to convention fly ash brick. 


\section{Acknowledgments}

The Authors thankfully acknowledge to Dr. C. L. Patel, Chairman, Charutar Vidya Mandal, and Er. V. M. Patel, Hon. Jt. Secretary, Charutar Vidya Mandal, Prof. (Dr.) Indrajit Patel, Principal, B.V.M. Engineering College, Vallabh Vidyanagar, Gujarat, India for their motivations and infrastructural support to carry out this research.

\section{Conflicts of interest}

None.

\section{References}

1. Alonso-Santurde, Coz RA, Viguri JR, Andrés A. Recycling of foundry by-products in the ceramic industry: Green and core sand in clay bricks. Journal of Construction and Building Material. 2012;7:96-106.

2. GS Patange, MP Khond, HJ Rathod, KB Chhadva. Investigation of foundry waste sand reclamation process for small and medium scale indian foundry. International journal of Industrial Engineering \& Technology (IJIET). 2013;3(1):1-6.
3. Chusid Michael, Miller Steven H, Rapoport Julie. The building bricks of sustainability. The Construction Specifier. 2009;1: 30-40.

4. Prasad HN, Prasad HG, Hamsagar C, et al. An approach for alternative solution in brick Manufacturing. International Journal of Science, Environment and Technology. 2014;3(3): 1105-1114.

5. Ajay Andodariya, Reshma L Patel, Jayesh Pitroda. Techno Economical study on Eco-Friendly Green Brick Production Using Reclaimed Sand Dust Waste: A Review. International Conference on Research and Innovations in Science, Engineering \& Technology. 2017;17-19.

6. Kulkarni A, Raje S, Rajgor M. Bagasse ash as an effective replacement in fly ash bricks. International Journal of Engineering Trends and Technology (IJETT). 2013;4: 4484-4490.

7. Sumathi A, Sarvana K. Compressive Strength of Fly Ash Brick with Addition of Lime, Gypsum and Quarry Dust. International Journal of Chem Tech Research. 2014;7(1):28-36. 